\title{
La privatización de los espacios públicos destinados al ocio y al turismo mediante la regulación del estacionamiento de vehículos. Análisis de casos en la isla de Mallorca
}

\author{
Miquel Àngel Coll Ramis \\ Miguel Seguí Llinàs \\ Universitat de les Illes Balears. Departament de Ciències de la Terra \\ uibgeotur@gmail.com \\ msegui@uib.es
}

\section{Resumen}

El avance de las políticas neoliberales a escala mundial ha provocado que haya aumentado la privatización de los recursos públicos, especialmente en un momento de crisis económica y necesidad de buscar nuevas fuentes de financiación por parte de la Administración. En este contexto, los espacios litorales destinados al ocio y al turismo tampoco se han salvado de la presión ejercida por parte de los gobiernos y de las empresas privadas, y han visto cómo su carácter colectivo se ha privatizado directa o indirectamente. La isla de Mallorca no se ha mantenido ajena a este proceso global y, durante los últimos años, se está observando un aumento de privatizaciones de espacios públicos. Para ello, una de las fórmulas utilizadas es la regulación del estacionamiento de los vehículos en el dominio municipal. Dicha iniciativa se ha convertido en una importante fuente de financiación para las poblaciones turísticas de la isla.

Palabras clave: espacio público; turismo; privatización; estacionamiento; Mallorca.

Resum. La privatització dels espais públics destinats a l'oci i al turisme mitjançant la regulació de l'estacionament de vehicles: Anàlisi de casos a l'illa de Mallorca

L'avanç de les polítiques neoliberals a escala mundial ha provocat que hagi augmentat la privatització dels recursos públics, especialment en un moment de crisi econòmica i de necessitat de cercar fonts noves de finançament per part de l'Administració. Dins d'aquest context, els espais litorals destinats a l'oci i al turisme tampoc s'han salvat de la pressió exercida per part dels governs i de les empreses privades, $i$ han vist com el seu caràcter públic s'ha privatitzat de manera directa o indirecta. L'illa de Mallorca no s'ha mantingut aliena a aquest procés global $i$, durant els darrers anys, s'hi està observant un augment de privatitzacions d'espais públics. Per això, una de les fórmules utilitzades és la regulació de l'aparcament dels vehicles dins el domini municipal, la qual cosa s'ha convertit en una important font de finançament per a les poblacions turístiques de l'illa.

Paraules clau: espai públic; turisme; privatització; estacionament; Mallorca. 
Résumé. La privatisation des espaces publics pour le tourisme de loisirs par la réglementation du stationnement des véhicules. Étude de cas sur l'île de Majorque

Les progrès des politiques néolibérales mondiales, a causé l'augmentation de la privatisation des ressources publiques, en particulier en temps de crise économique, ainsi que la nécessité de trouver de nouvelles sources de financement du gouvernement. Dans ce contexte, les zones côtières pour les loisirs et le tourisme n'ont pas été épargnées par la pression des gouvernements et des entreprises privées, et ont vu leur caractère public directement ou indirectement privatisé. L'île de Majorque n'est pas restée à l'abri de ce processus global, et ces dernières années, on assiste à une privatisation croissante des espaces publics. Pour ce faire, l'une des formules utilisées est la réglementation du stationnement des véhicules dans le domaine public, qui est devenu une source importante de financement pour les villes touristiques de l'île.

Mots-clés: espace public; le tourisme; la privatisation; stationnement; Majorque.

Abstract. The privatization of public leisure and tourism spaces by regulating the parking of vehicles: A case analysis on the island of Majorca

The advance of neoliberal policies worldwide has led to the increasing privatization of public resources, especially in the midst of the economic crisis, which has required seeking new sources of government funding. In this context, coastal leisure and tourism areas have not escaped from the pressure exerted by governments and private companies to privatize such public areas either directly or indirectly. The island of Majorca has not remained unaffected by this global process, and has seen an increase in the privatization of public spaces in recent years. One of the formulas used to privatize these spaces is the regulation of the parking of vehicles in the public domain, which has become a major source of funding for the tourist towns on the island.

Keywords: public space; tourism; privatization; parking; Mallorca.

\begin{aligned} & \multicolumn{2}{c}{ Sumario } \\ & Introducción $\begin{array}{l}\text { La privatización de los espacios públicos } \\ \text { destinados al ocio y al turismo mediante } \\ \text { la regulación del estacionamiento. }\end{array} \\ &$ Objetivos y metodología $\begin{array}{l}\text { Estudio de casos en Mallorca } \\ \text { Marco teórico }\end{array} \\ &$ Conclusiones \\ & Referencias bibliográficas \end{aligned}

\section{Introducción}

Este trabajo plantea una temática poco estudiada hasta el momento: el uso privado de espacio público para el estacionamiento de vehículos en zonas turísticas de la isla de Mallorca. En efecto, la privatización del espacio público es un tema con cierta literatura, ya sea desde el punto de vista de la geografía como de las ciencias afines, como la sociología e incluso la antropología. Sin embargo, la 
mayor parte de las aportaciones se refieren a zonas urbanas consolidadas (plazas o parques urbanos, etc.), pero no a entornos no urbanos (zonas de playas, recursos turísticos puntuales, etc.).

Partiendo de la idea de que el espacio geográfico es el reflejo de la sociedad y de las relaciones que se establecen en ella (Hiernaux y Lindón, 1996), no es de extrañar que, en el caso de Mallorca, exista una clara relación de dependencia entre el espacio y el turismo, al ser esta la actividad económica hegemónica de la isla. En este sentido, el gran desarrollo turístico asociado al producto de sol y playa que se experimentó durante la segunda mitad del siglo $\mathrm{xx}$ provocó una fuerte presión urbanizadora sobre la franja costera, con lo que muchos espacios naturales del litoral fueron destruidos (Picornell, 1989; Salvà, 1990; Seguí, 2006; Murray et al., 2008). Este modelo de desarrollo turístico consumidor de territorio se encontró con el rechazo de una parte de la sociedad, lo que produjo las primeras manifestaciones en defensa del territorio (Seguí, 2006).

Precisamente la movilización de la sociedad local fue la que permitió la protección de espacios naturales que estaban amenazados por los intereses urbanizadores, como fue el caso de la isla de Sa Dragonera ${ }^{1}$, la cual fue comprada el año 1988 por el Consell Insular de Mallorca, con lo que se convirtió en un espacio público protegido. En otros casos, las compras realizadas por parte del Govern de les Illes Balears, como, por ejemplo, la finca de Son Real ${ }^{2}$, en el año 2002, o la finca de Planicia ${ }^{3}$, en 2009, reflejan que la Administración pública también ha comprado fincas privadas no solo para protegerlas desde el punto de vista ambiental, sino también para poder ofrecer espacios destinados al libre uso y disfrute de la sociedad local y/o para la promoción turística.

Sin embargo, esta faceta de la Administración pública como generadora de zonas al servicio de la ciudadanía contrasta con otras situaciones más recientes, en las que el poder público está siendo el que promueve privatizaciones directas o indirectas de los espacios comunes, tal y como se analiza en este artículo. Durante los últimos años, y coincidiendo con un contexto generalizado de crisis económica, las administraciones públicas han visto cómo sus ingresos han disminuido notablemente, lo cual ha dado pie a un cierto auge de las políticas privatizadoras neoliberales dentro de la propia Administración, que ha visto en el espacio común una fuente de ingresos para su subsistencia.

\section{Objetivos y metodología}

El artículo se plantea como un estudio de casos sobre el auge de los procesos de privatización del espacio público, con finalidades recaudatorias para el erario. En este sentido, una de las fórmulas que más se está extendiendo es la creación

1. En el año 1995, Sa Dragonera fue declarada parque natural en aplicación de la Ley 4/89 de espacios naturales, para asegurar definitivamente su protección medioambiental.

2. La finca de Son Real se localiza en la costa nordeste de Mallorca.

3. La finca de Planícia se ubica en la sierra de Tramuntana. 
de zonas de estacionamiento regulado de vehículos. Para analizar este fenómeno, se han seleccionado una serie de casos en la isla de Mallorca, a partir del cumplimiento de tres criterios:

1. Que sean aparcamientos situados en zonas de indudable interés turístico,

2. con unas características geonaturales especiales, lo cual provoca que la disponibilidad de espacio para el estacionamiento de vehículos sea limitada

3. y que se hayan privatizado con el beneplácito de la Administración pública, lo cual genera malestar entre la ciudadanía.

Para la identificación de posibles casos que cumplan estos criterios, en primer lugar, se han identificado los principales lugares de interés turístico según la información de promoción turística, que aparece en las webs oficiales de las administraciones públicas de la isla ${ }^{4}$. Posteriormente, mediante el programa ArcGIS 9.0, se han georreferenciado los aparcamientos sobre una ortofoto del año 2012. A continuación, se ha procedido al filtraje de casos en función de dos variables, que limitan la disponibilidad de aparcamiento (una limitación física del propio terreno y otra de tipo normativo). En este sentido, a partir de un modelo digital de elevaciones y las figuras de protección que establece el Plan Territorial Insular de Mallorca, se han seleccionado aquellos aparcamientos situados en zonas con una pendiente del terreno superior a un 20\% y/o que están rodeados por alguna figura de protección territorial que impida ampliar la disponibilidad de nuevos aparcamientos.

Finalmente, se ha realizado un último proceso de filtraje, en función de si los aparcamientos seleccionados eran zonas de aparcamiento público que han sido privatizados, lo cual ha ocasionado malestar entre la población local. Para ello, se ha llevado a cabo una búsqueda a través de las hemerotecas de los principales diarios de la isla (Última Hora, Diario de Mallorca y El Mundo Baleares). Como resultado final de este proceso de búsqueda, se han identificado cinco casos de estudio, dos de ellos en relación con elementos arquitectónicos y culturales particulares (el casco antiguo de Valldemossa y el monasterio de Lluc), y el resto, en zonas vinculadas al turismo de playa (playa de Formentor, playa de Es Trenc y playa de Sa Calobra-Torrent de Pareis).

\section{Marco teórico}

La revisión bibliográfica sobre el concepto de espacio público permite constatar la inexistencia de una definición universal, más bien existen numerosos enfoques y corrientes teóricas alrededor de su conceptualización (Cisneros, 2003; Estévez, 2012). Sobre el punto de partida de la configuración del espacio público, algunos autores (Habermas, 1989; Arendt, 2009) lo asocian con el nacimiento del ágora de las ciudades griegas. En cambio, otros investigadores

4. Govern de les Illes Balears (<http://www.illesbalears.es/esp/mallorca/home.jsp >). Consell Insular de Mallorca (<http://www.infomallorca.net/>). 
como Carmona et al. (2008) lo han relacionado con el nacimiento de los foros de las ciudades romanas. Se trataba de lugares de encuentros y debates, tanto académicos como políticos, que posteriormente acabarían siendo unos espacios para el ocio de los ciudadanos (juegos, paseos, etc.), aunque algunos autores como Sennet (1994) han cuestionado su carácter público, argumentando que no eran accesibles para todos los habitantes de la ciudad, ya que existía una distinción social en su uso y disfrute.

No será hasta la llegada de la modernidad, con la creación de los primeros estados nacionales en los siglos XV y XVI, cuando entra en escena «lo público» en sentido estricto, que resulta análogo a lo estatal, frente a «lo privado», que quedaría relegado al mercado y a la sociedad de burgueses (Habermas, 1999). Durante esta etapa histórica, y bajo la tutela de las naciones estado, se crean espacios públicos en las urbes. Dichos espacios se destinan a dar servicio a una mayor periodicidad de las ferias, las cuales, si bien vienen constituyéndose desde el siglo XII, es en este periodo en que se van a hacer más patentes en la vida de la sociedad (Díaz, 2013). A medida que fue consolidándose el poder público, proliferaron otros espacios comunes en las ciudades, que fueron destinados a otros fines de carácter lúdico, artístico o cultural. Este proceso de consolidación de espacios comunes en las ciudades se expandió progresivamente hacia otros lugares (el litoral, la montaña, las riberas de los ríos y lagunas, etc.), quedando plasmado su carácter público en las leyes de muchos países (como, por ejemplo, el caso de la Constitución en España). En este sentido, cabe mencionar que las legislaciones del espacio público, en general, se rigen sobre la base de la preservación de tres criterios básicos:

1. Que sea común a todos, por tanto, que represente el interés general por encima de los intereses particulares.

2. Que sea visible.

3. Que sea abierto y accesible a todos los ciudadanos (Rabotnikof, 2005).

No obstante, a partir de la segunda mitad del siglo xx, el concepto de espacio público está sufriendo una acelerada resignificación en la misma medida en que la gobernanza neoliberal está cambiando toda noción de lo público para su desmontaje y privatización (Low, 2005; Carmona, 2010; Ardura, 2014), en unas ocasiones bajo el paraguas de aumentar la cantidad y la calidad de los servicios (Peck y Tickell, 2002; Mordue, 2007) y, en otras, con la necesidad de conservarlo ecológicamente o evitar su degradación. Sin embargo, tal y como apuntan algunos autores como McKenzie (1994), son los problemas de financiación que tienen las administraciones locales el principal motivo por el cual los gobiernos municipales están impulsando privatizaciones del espacio común.

No obstante, sea cual sea el motivo, la realidad parece indicar que se está produciendo, a escala global, una consolidación de las políticas neoliberales dentro de la gestión pública (Mordue, 2007; Prada, 2011), lo que supone un auge en la aplicación de estrategias de gestión del sector privado dentro del ámbito público. El único objetivo que persiguen estas políticas es el de esti- 
mular el consumo privado fomentando la mercantilización del espacio común. Esta dinámica de transformación de la propiedad pública en propiedad privada del espacio puede ser explicada como «un proceso en el que el acceso público a ciertos recursos y espacios ha adquirido valor en la lógica del capital, lo que supone el desplazamiento de los derechos colectivos por derechos individuales de propiedad y beneficio» (Cruz et al., 2012: 157). Con lo cual, tal y como advierten algunos autores (Hughes, 1999; Paquot, 2000; Astleithner y Hamedinger, 2003), las personas son vistas como simples consumidoras y no como ciudadanas, con lo cual se ven limitados sus derechos de acceso y uso del espacio público en función de su capacidad económica.

Todo ello ha llevado a que determinados autores, como Burgos (2011: 93), hayan concluido que «estas prácticas de privatización y exclusión demuestran que los imperativos sociales de bienestar público son superados por modelos hegemónicos, caracterizados por su carácter deficitario de ciudadanía». Por otra parte, este retroceso del espacio público ha ocasionado el surgimiento de otras voces críticas (Fainstein, 1994) que advierten del peligro que supone la conversión de espacios públicos en espacios privatizados o pseudopúblicos, en los cuales la libertad y la diversidad social se pierden y se crea un entorno exclusivo que contribuye a la fragmentación socioespacial (Prévôt, 2001; Bellet, 2007).

\section{La privatización de los espacios públicos destinados al ocio y al turismo mediante la regulación del estacionamiento. Estudio de casos en Mallorca}

Durante los últimos años, los ayuntamientos de la isla han visto cómo la que había sido una de sus principales fuentes de financiación propia, es decir, los ingresos correspondientes a las tasas ligadas a la actividad urbanística, han disminuido drásticamente, lo cual les ha obligado a buscar nuevas fórmulas de financiación. Esta necesidad ha favorecido la aplicación de políticas privatizadoras en determinados servicios públicos y el aumento de tributos municipales.

Dentro de este contexto, la regulación del estacionamiento en el dominio público es una práctica que está adquiriendo fuerza en los municipios de la isla, especialmente en aquellos donde la actividad turística tiene mayor protagonismo. Su mecanismo es sencillo. Consiste en obligar a pagar una tasa para estacionar el vehículo, lo cual permite disfrutar del lugar visitado (por ejemplo: una playa). $Y$ es que, a pesar de que el acceso a cualquier espacio público es libre, en muchos casos, sin el pago de una tasa de estacionamiento, se hace prácticamente imposible su disfrute, debido a que su acceso exige enormes dificultades (realizar largas caminatas, atravesar zonas de maleza, etc.).

En España, esta práctica está amparada por la ley reguladora de las haciendas locales, aprobada por el Real Decreto legislativo 2/2004, de 5 de marzo, la cual establece que los ayuntamientos pueden imponer tasas para el aprovechamiento del dominio público local, mediante la creación de ordenanzas municipales reguladoras del estacionamiento. En dichas ordenanzas, se establecen aspectos como las zonas afectadas por la regulación del aparcamiento, las tarifas, las infracciones, las sanciones y el sistema para su explotación. 
Por lo que se refiere a la explotación de la gestión de los aparcamientos en el espacio público, puede ser llevada a cabo tanto desde la propia Administración local como por empresas privadas. Estas deben ceñirse a concesiones que les obligan a pagar, a la Administración pública, un canon fijo y/o un porcentaje de los ingresos recaudados. Un estudio del Consell Insular de Mallorca cifró, en el año 2006, en un 94,28\% la eficacia en la recaudación de las tasas de estacionamiento en dominio público, lo cual generó, en el conjunto de municipios de Mallorca, un beneficio anual de 7.219.714 euros (Alegre y Pou, 2009). El hecho de que sea un sistema de recaudación eficaz y genere importantes ingresos es lo que justifica que su presencia haya proliferado en la isla. Sin embargo, estas situaciones de privatización del acceso a espacios públicos destinados al ocio y al turismo evidencian la permisividad de los gobernantes, que frecuentemente centran más sus esfuerzos en satisfacer intereses privados en vez de proteger el interés común (García, 2004), tal y como se analiza a continuación.

\section{Valldemossa}

Esta pequeña localidad situada en la sierra de Tramuntana es uno de los mayores atractivos turísticos de la isla. Se trata de uno de los puntos que recibe más visitas de turistas a lo largo del año. La zona urbana está dividida en dos espacios por una carretera principal. En un lado, queda la parte antigua del pueblo y lugar visitado por los turistas por su atractivo patrimonial e histórico, especialmente la cartuja donde se hospedaron George Sand y Chopin, y, en el otro lado, la zona más moderna y de desarrollo urbano reciente.

La normativa es muy restrictiva en referencia al hecho de acceder motorizado hacia la parte antigua del pueblo, que ha sido transformada en zona prioritaria para los peatones y su acceso con vehículo a motor solamente es permitido a la población residente. La motivación argumentada para justificar estas restricciones se basa en las especiales condiciones urbanísticas y de protección de esta parte del casco urbano y nunca se hace mención a ningún aspecto relacionado con el turismo. Sin embargo, la casi totalidad de visitantes que llegan al pueblo lo hacen por medio de automóvil propio, con lo cual se produce una gran afluencia diaria de coches. En consecuencia, existen dos aparcamientos de pago tarifado (ORA) situados junto a la carretera, en la parte nueva del municipio. Además, la práctica totalidad de las calles de esta zona están señalizadas como área de pago (figura 1), para evitar su utilización como evasión frente a los dos aparcamientos.

Por este motivo, desde el año 2001, momento en que entró en vigor la ordenanza municipal de aparcamiento, todo turista o persona que no resida en el municipio, cuando visite la localidad en coche, se verá obligado a pagar una tasa de estacionamiento. Las tarifas oscilan desde un mínimo de 60 minutos, cuyo coste es de 0,75 euros, hasta un máximo de 10 horas, por un importe de 3,5 euros. Este sistema de recaudación de aparcamiento tarifado permite al Ayuntamiento disfrutar de una excelente situación económica. El consistorio no conoce la crisis y sus presupuestos gozan de una buena salud, tal y como 


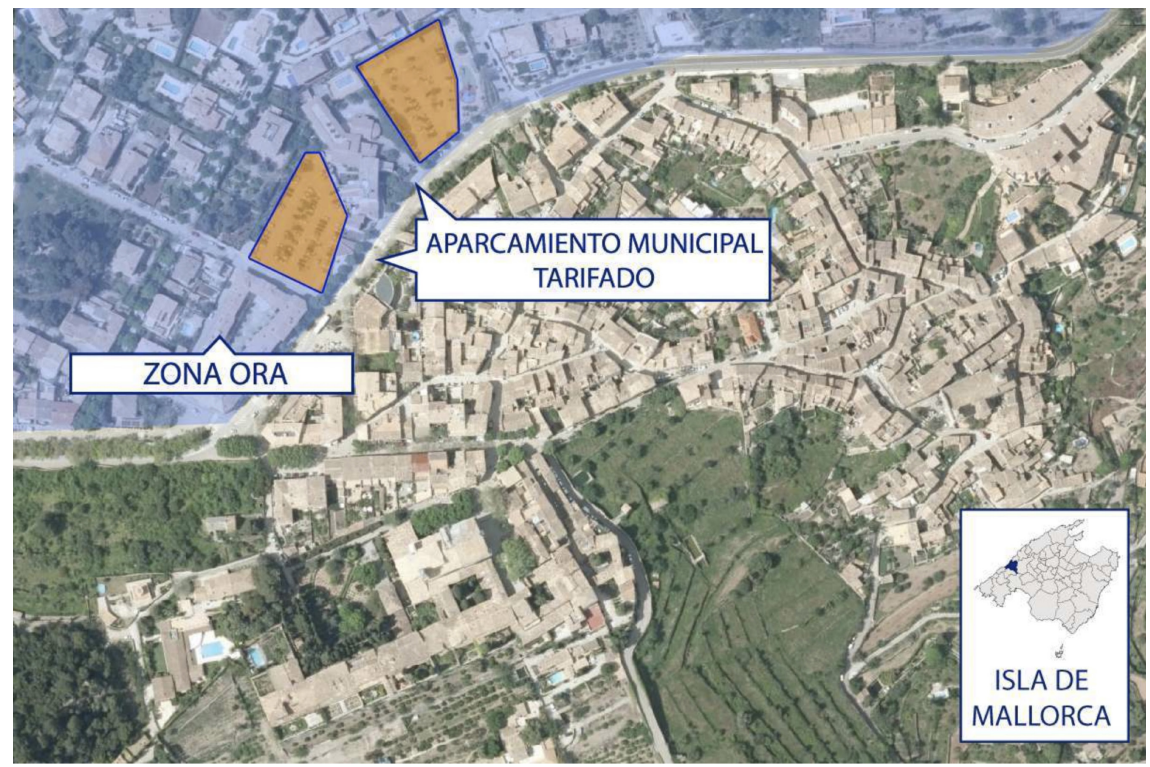

Figura 1. Localización de las zonas de aparcamiento tarifado en el casco urbano de Valldemossa.

Fuente: elaboración propia.

reconocía su alcalde en un artículo publicado en el Diario de Mallorca el día 9 de octubre de $2011^{5}$ :

[...] la crisis no afecta a todos por igual: unos tanto y otros tan poco. De los 53 municipios de la isla, solo hay un alcalde que reconoce abiertamente, al preguntarle sobre los recortes y las medidas de austeridad de su Ayuntamiento, que no sabe de qué le están hablando ni falta que le hace. Es el de Valldemossa. El alcalde Francesc Mulet arguye que la buena temporada turística les ha permitido que la caja esté llena. Valldemossa recauda una buena cantidad con la ORA de los aparcamientos municipales y, además, se lleva un porcentaje de las entradas de la cartuja.

\section{Monasterio de Lluc (Escorca)}

Este monasterio aglutina a la mayor parte de los habitantes del municipio de Escorca, hasta tal punto que pueblo y monasterio se confunden. Tradicionalmente, este monasterio ha sido el centro espiritual de la isla y el lugar de atracción de muchos peregrinos, especialmente durante los fines de semana y las grandes festividades. Al mismo tiempo, por su situación en el centro de la sierra de Tramuntana

5. <http://www.diariodemallorca.es/part-forana/2011/10/09/valldemossa-unico-municipionecesita-recortes/710173.html> [consulta: 21 febrero 2014]. 


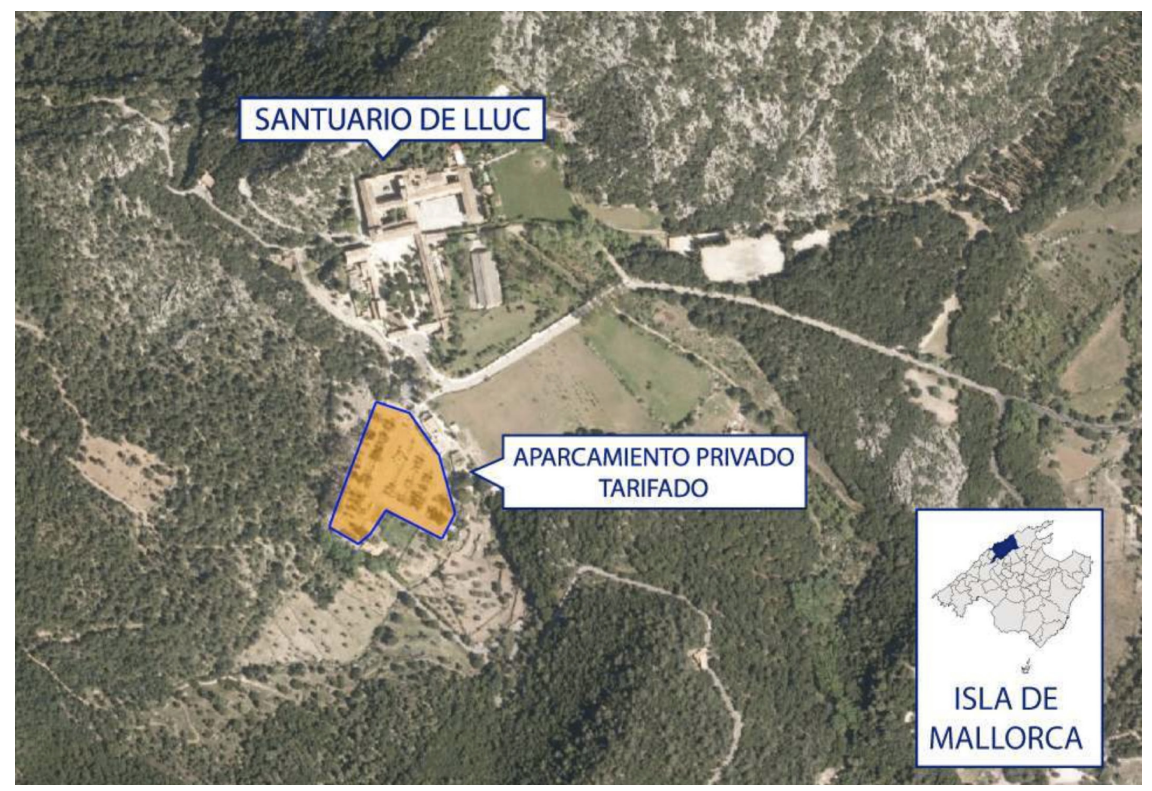

Figura 2. Localización del aparcamiento tarifado del monasterio de Lluc (Escorca).

Fuente: elaboración propia.

(Patrimonio de la Humanidad), y rodeado de las mayores altitudes de dicha sierra, es el punto de partida de muchas excursiones y actividades de senderismo que tienen lugar en su parte central. Estos dos factores hacen de este monasterio un lugar muy frecuentado que demanda un gran aparcamiento para dejar los coches y poder realizar la visita al santuario o bien iniciar los recorridos a pie.

Precisamente esta necesidad ha sido aprovechada con un plan de connivencia entre el obispado de Mallorca (propietario de los terrenos) y el Ayuntamiento de Escorca, mediante el cual el obispado convierte una parte de sus propiedades en un amplio aparcamiento de varios centenares de plazas, con un servicio de pago (figura 2). Al mismo tiempo, el Ayuntamiento impide el estacionamiento en las pocas calles que conforman la localidad y que le son adyacentes, además de cerrar el aparcamiento municipal, que se encontraba un poco más lejos, en una antigua zona de acampada.

Este proyecto se inició en el año 2012, bajo la denominación de Plan de Mejora de Acogida de los Visitantes, y fue justificado bajo el paraguas de la necesidad de recaudar fondos para el mantenimiento de los servicios que se prestan en el santuario, especialmente el museo y el jardín botánico. Este argumento basado en la necesidad de privatizar un espacio público determinado (aunque en este caso sea privado), para poder mejorar sus servicios a la ciudadanía, suele ser muy usado por los gestores políticos a la hora de justificar su sumisión frente a los intereses del capital privado. 


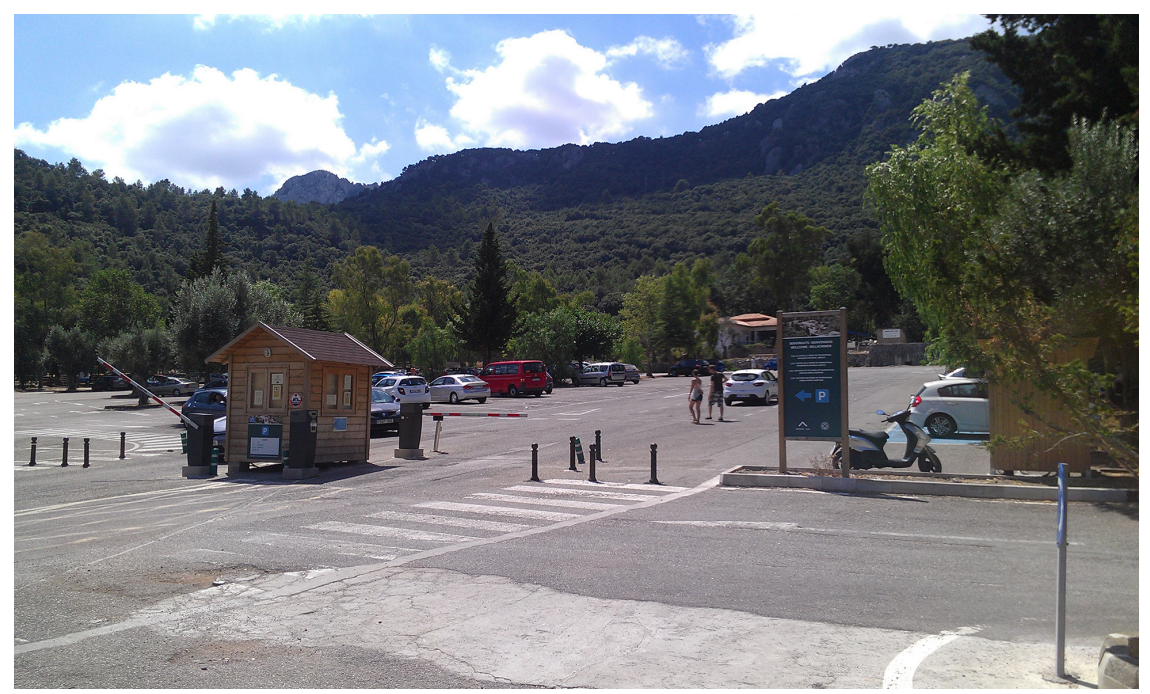

Figura 3. Entrada al aparcamiento tarifado del santuario de Lluc (Escorca).

Fuente: elaboración propia (2014).

Inicialmente, el precio del aparcamiento era una tarifa única de 4 euros por día y coche, y ello daba derecho a entrar en el museo de Lluc, que hasta entonces era de pago. En pocos meses, el número de visitantes del museo aumentó de forma espectacular, sin embargo, su coste fue motivo de críticas por parte de la sociedad local, por considerarlo abusivo. Esto provocó tal revuelo que, al cabo de pocos meses, se aplicó un nuevo sistema tarifario que distinguía entre residentes y turistas ${ }^{6}$. El nuevo sistema establecía que la primera hora de aparcamiento costaba 2 euros y, a partir de ese momento, el pago se tarifaría por minutos, estableciéndose un precio máximo diario para residentes de 3,98, y de 4,80 euros para los no residentes. Si querían visitar el museo, unos y otros debían pagar 1,5 euros extra por persona. No obstante, parece ser que este sistema tarifario tampoco consiguió satisfacer a los gestores del aparcamiento, que optaron por una nueva política de precios ${ }^{7}$. Así pues, desde el mes de septiembre de 2013, se estableció un pago de 2 euros por vehículo y día para los residentes y de 6 euros por vehículo y día para los turistas. En el caso de que turistas o residentes quieran visitar el museo, pueden canjear su tique de aparcamiento por otro que les permite acceder libremente a esta instalación (figura 3).

6. <http://ultimahora.es/mallorca/noticias/part-forana/2013/89196/aparcar-lluc-cuesta-ahorados-centimos-por-minuto-tiquet-incluye-entrada-museo.html> [consulta: 21 febrero 2014].

7. <http://ultimahora.es/mallorca/noticias/part-forana/2013/108971/aparcamiento-lluc-cambia-por-tercera-vez-tarifas-para-potenciar-llegada-residentes.html> [consulta: 21 febrero 2014]. 


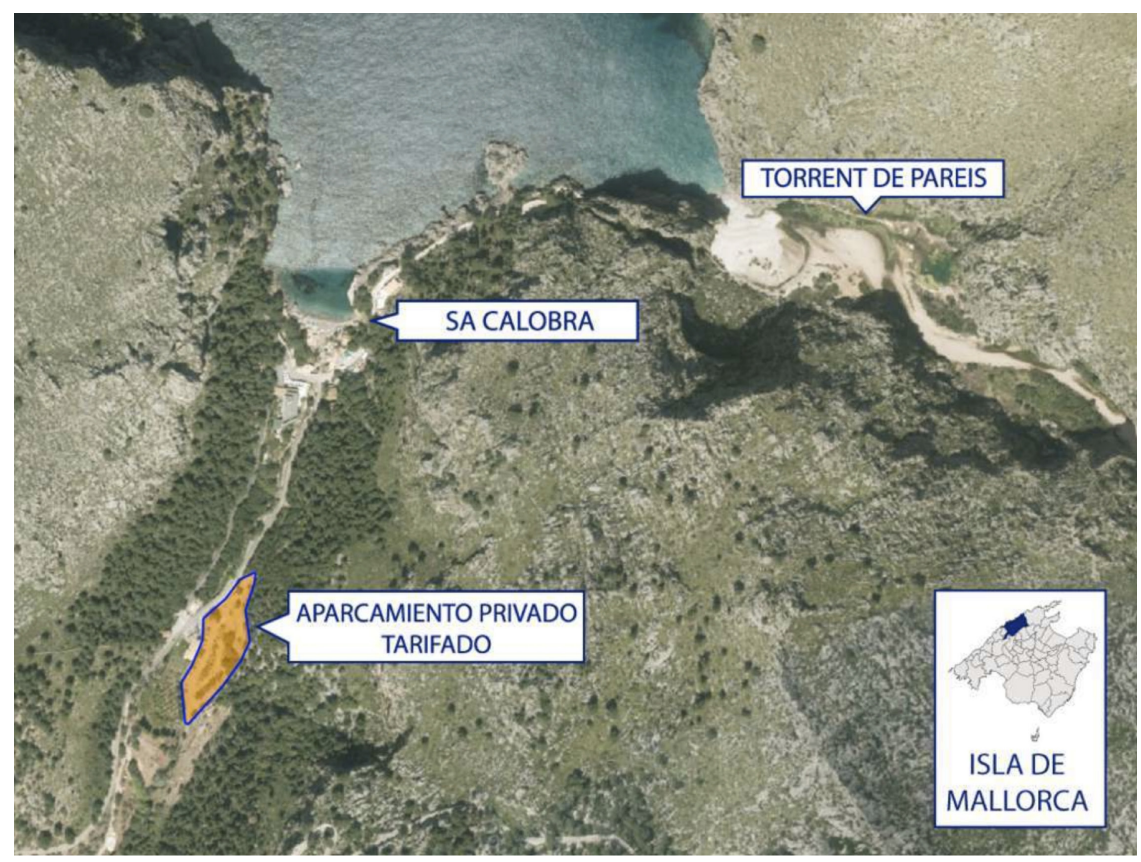

Figura 4. Localización del aparcamiento tarifado de Sa Calobra (torrente de Pareis).

Fuente: elaboración propia.

\section{Sa Calobra-Torrente de Pareis (Escorca)}

En el municipio de Escorca también encontramos otro de los atractivos turísticos más visitados de la isla, como es la desembocadura del torrente de Pareis, en Sa Calobra (declarado Monumento Natural por el Govern Balear en el año 2003). A pesar de su difícil accesibilidad, multitud de turistas y residentes visitan este espacio de gran belleza natural.

Las características del relieve de la zona limitan el lugar disponible para el estacionamiento de vehículos (figura 4). Esta gran demanda y una oferta limitada han dado pie a que el aparcamiento gratuito sea prácticamente inexistente en la zona, y si se quiere visitar la desembocadura del torrente de Pareis con su hermosa cala, solo cabe la posibilidad de dejar el vehículo en la zona privada destinada a ello (figura 5).

El aparcamiento es de propiedad municipal, pero está gestionado por una empresa privada que, en el año 1999, obtuvo su explotación durante 25 años mediante un concurso público. Se caracteriza por su estacionalidad, ya que, al terminar la temporada turística (de mayo a septiembre), su demanda se reduce drásticamente y el estacionamiento pasa a ser gratuito. El hecho de que solo sea de pago durante unos meses del año justificaría su elevado precio (2,80 euros por hora, hasta una tarifa máxima de 10 euros por día). 


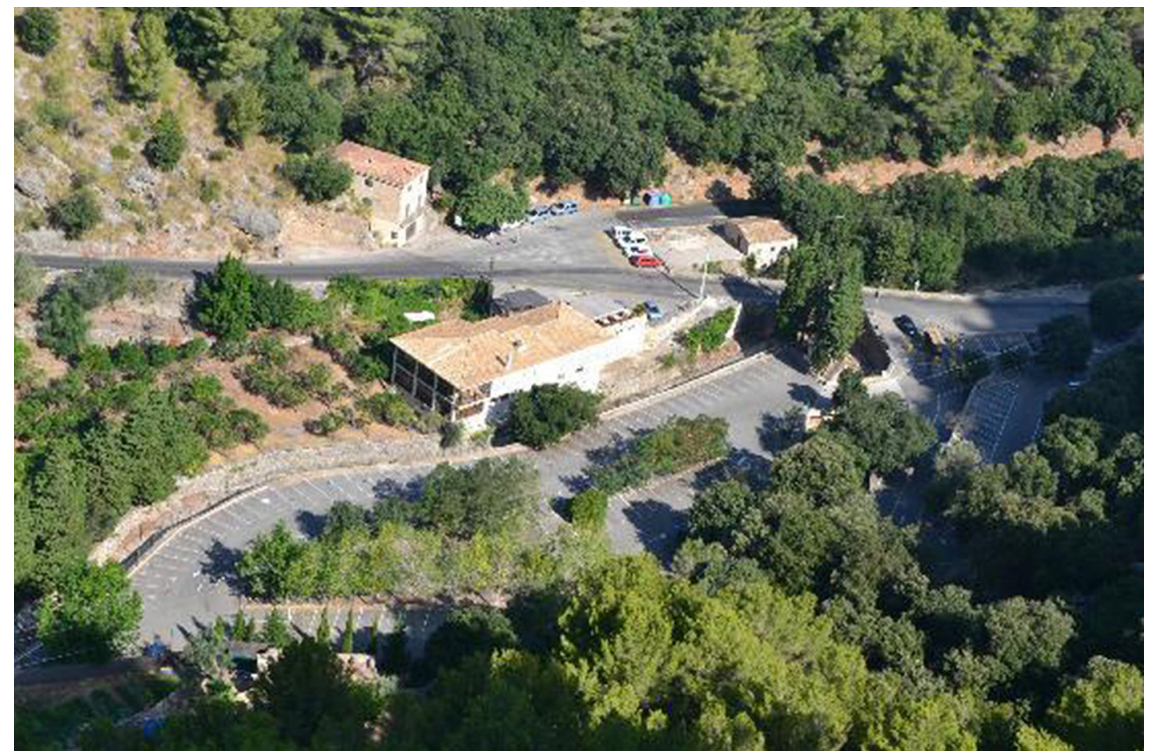

Figura 5. Imagen del aparcamiento tarifado de Sa Calobra (torrente de Pareis).

Fuente: elaboración propia (2014).

\section{Formentor (Pollença)}

La playa de Formentor, una de las más emblemáticas de Mallorca y de larga tradición turística, es un buen ejemplo de privatización del acceso a un espacio público. Formentor es, teóricamente, una zona urbana del municipio de Pollença, situado al norte de la isla. Esta urbanización data de las décadas de 1960 y 1970 y se construyeron pocas edificaciones, todas ellas de alto standing y correspondientes a un número reducido de familias de elevado poder adquisitivo que han impedido la finalización de su acondicionamiento. Esta no cuenta con servicios y, por lo tanto, no puede ser recepcionada por el Ayuntamiento. De esta forma, los vecinos mantienen el privilegio de la exclusividad e impiden que otras personas se instalen en el área, ni siquiera permiten que aparquen en la cercanía de sus viviendas, porque las pocas calles que hay, al no estar recepcionadas por el Ayuntamiento, mantienen su estatus de titularidad privada. De este modo, al existir únicamente la carretera que llega a Formentor, no hay posibilidad de dejar los vehículos en toda la zona (figura 6).

Esta falta de espacio para coches es aprovechada por el hotel Formentor, que dispone de un gran aparcamiento de pago en sus propiedades, que funciona únicamente durante la temporada turística (de mayo a septiembre) y que constituye la única forma legal de estacionar los vehículos para poder ir a la playa (figura 7). 


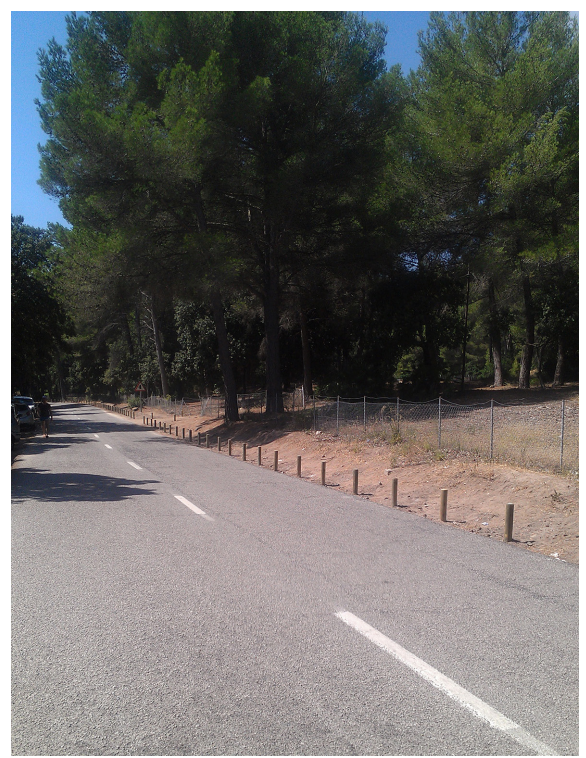

Figura 6. Pilones de madera que impiden estacionar en el arcén de la carretera de Formentor. Fuente: elaboración propia (2014).

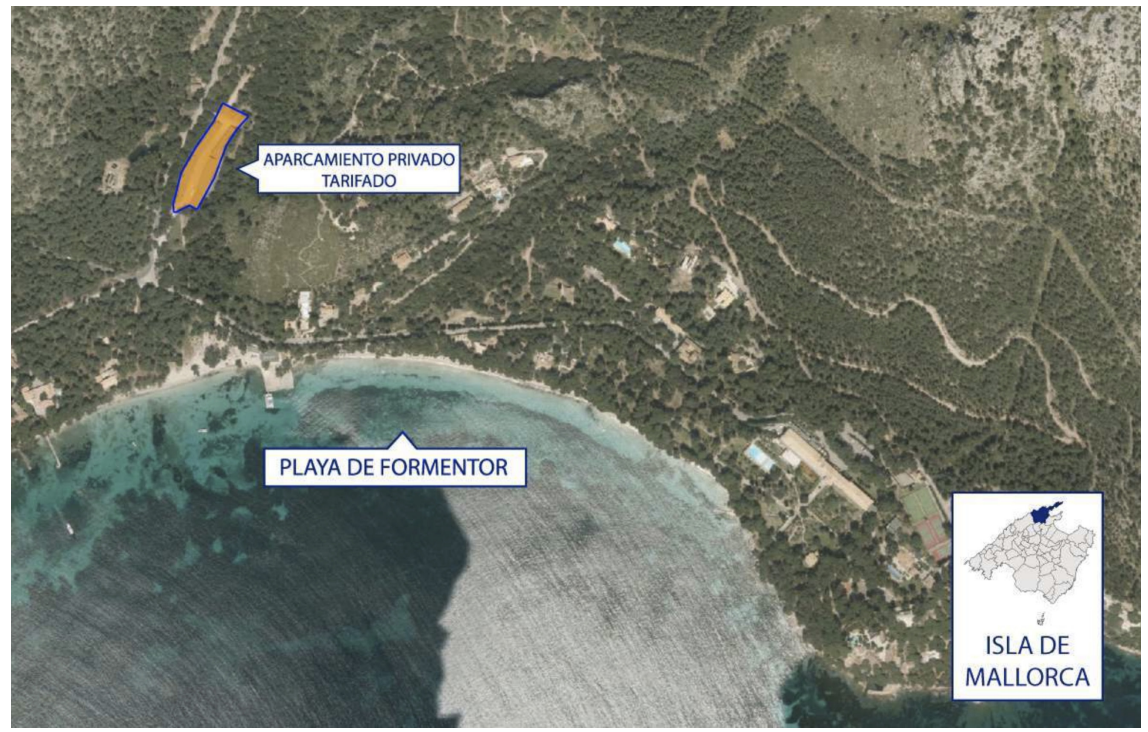

Figura 7. Localización del aparcamiento tarifado de Formentor.

Fuente: elaboración propia. 
Sin embargo, esta cuestión viene generando un gran debate social entre la sociedad local, que reclama el uso público de este privilegiado enclave de la geografía mallorquina, tal y como recogía una noticia publicada en el Diario de Mallorca el día 4 de enero de $2011^{8}$ :

[...] la cuestión ya fue objeto de polémica el pasado verano, cuando trascendió que un guarda privado impedía el paso de coches a los viales de dicha urbanización —aún no recepcionada por el Ayuntamiento-y, por tanto, restringiendo el acceso al área del litoral. Los vehículos eran desviados hacia un aparcamiento cercano, explotado por el hotel Formentor, en el que se cobraba cinco euros por dejar el coche. [...] Durante la última sesión plenaria, el edil del Partido Socialista de Mallorca intervino para pedir al equipo de gobierno que no consienta que la próxima temporada se violen los derechos de los ciudadanos y que, tal y como establece el informe, el Ayuntamiento garantice el uso público de los viales de Formentor.

A pesar de la polémica que suscita, el conflicto parece estar lejos de solucionarse, si tenemos en cuenta que, en el año 2011, el precio del aparcamiento era de 5 euros por coche y día, y que, durante el año 2014, el precio ascendió a 10 euros por coche y día. Esta situación evidencia la permisividad de la Administración pública, que favorece el negocio privado para poder acceder a un espacio público como es la playa de Formentor.

\section{Es Trenc (Campos)}

Constituye quizás la forma más compleja de limitar y controlar el acceso público a la mayor playa virgen que queda en la isla: Es Trenc (Campos). Gracias a un fuerte movimiento ecologista que evitó su urbanización, esta playa es uno de los principales atractivos turísticos de la isla, lo que provoca una gran afluencia de visitantes en verano, atraídos por la calidad de sus aguas, la belleza de su sistema dunar y el pinar adyacente.

La playa de Es Trenc tiene una extensión aproximada de unos $2 \mathrm{~km}$ y dispone de un solo acceso directo en la parte central de la playa, que termina con un aparcamiento, sin otra posibilidad de dejar el coche (figura 8). Este aparcamiento es privado, con licencia municipal desde hace más de dos décadas, es decir, anterior a cuando la zona fue protegida a través de la Ley de Espacios Naturales (LEN, 1991). Este aparcamiento dispone aproximadamente de un millar de plazas para vehículos, con una tarifa única para todo el día de 6 euros para coches, 2 euros para motos y 1 euro para bicicletas, y está abierto durante todo el año.

Además de este aparcamiento, se puede acceder a la playa desde dos núcleos urbanos situados en sus extremos, uno en el municipio de Campos - Ses Covetes - y otro en el municipio de Ses Salines - Sa Colònia de Sant Jordi(figura 9). En estos dos núcleos, sus ayuntamientos respectivos han implantado

8. <http://www.diariodemallorca.es/part-forana/2011/01/04/informe-municipal-1996-defendio-publico-viales-formentor/633331.html> [consulta: 21 febrero 2014]. 


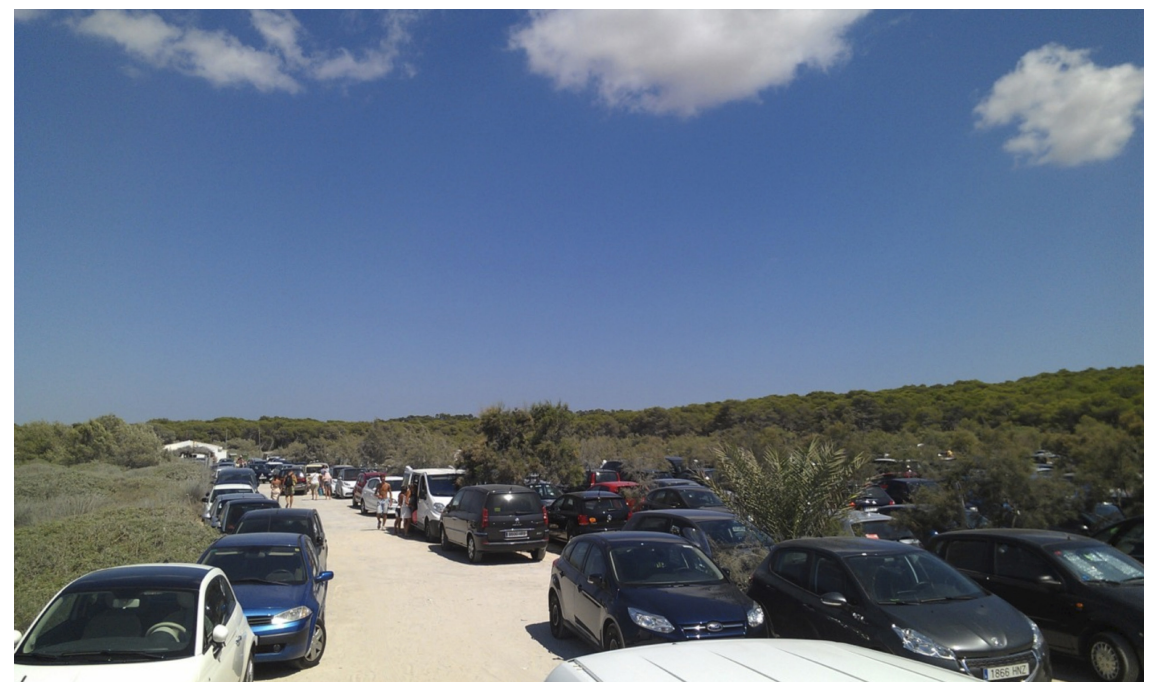

Figura 8. Vista general del aparcamiento privado situado en la parte central de la playa de Es Trenc.

Fuente: elaboración propia (2014).

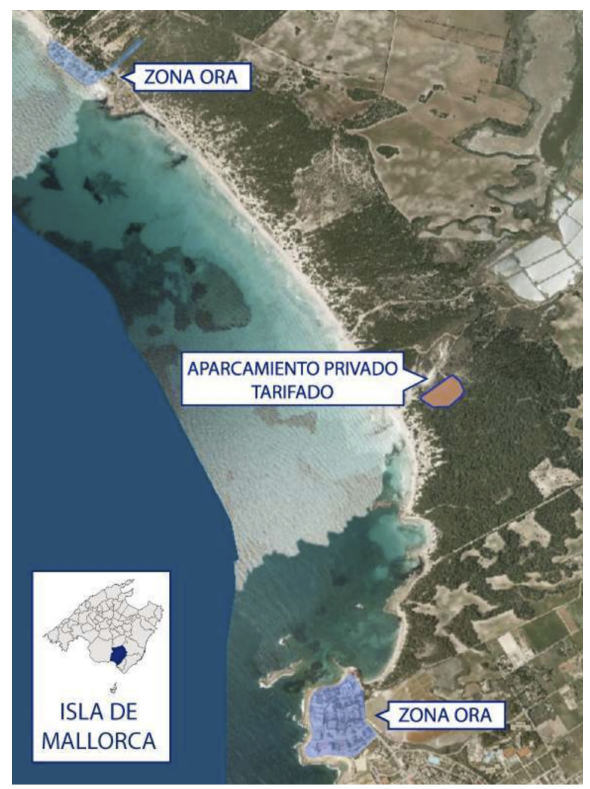

Figura 9. Localización de los aparcamientos tarifados en la playa de Es Trenc.

Fuente: elaboración propia. 
un sistema regulado de aparcamiento de pago, tarifado por horas, desde el 15 de junio hasta el 15 de septiembre, entre las 10 y las 19 horas. Para hacerse una idea de los precios del estacionamiento, en el caso de Ses Covetes, son los siguientes: una hora, un euro; dos horas, dos euros; tres horas, tres euros, y la tarifa diaria, cinco euros. Para la gestión del servicio, en el año 2013, el Ayuntamiento de Campos sacó a concurso su adjudicación por un período de tres años, con un canon fijo mínimo para el Consistorio de 40.000 euros anuales, más el 5\% de las ganancias de cada temporada?

A pesar del claro beneficio económico, el Ayuntamiento lo justifica exclusivamente por motivos de seguridad, alegando la necesidad de prohibir aparcar de forma masiva en la calzada de la carretera, lo que originaba atascos y problemas de accesibilidad en casos de emergencia, tal y como argumentaba el consistorio de Campos en una noticia aparecida en el Diario de Mallorca el día 23 de mayo de $2011^{10}$ :

[...] el consistorio, defiende las ventajas que tienen los habitantes empadronados en el municipio y también resalta la regulación de la circulación, facilitando además la llegada de la ambulancia y del camión de bomberos, u otros servicios, en casos de emergencias, aparte del pertinente transporte público. [...] El sistema de recaudación goza de buena acogida entre los residentes, los cuales están eximidos de su pago, y ven con buenos ojos que el Ayuntamiento de Campos pueda recaudar dinero con esta medida. Todo lo contrario sucede con los visitantes foráneos, que ven en la medida un simple y flagrante afán recaudatorio del Ayuntamiento [...].

\section{Conclusiones}

La privatización (directa o indirecta) de espacios públicos destinados al ocio es un proceso que, en la actualidad, se encuentra en auge a nivel mundial. En el caso de Mallorca, las playas o los lugares de interés turístico siguen siendo de acceso público y gratuito, pero se está limitando su uso a través de la implantación de aparcamientos de pago. En este caso, su finalidad no es la de impedir el acceso a nadie, como sería el caso de otras regiones del mundo (por ejemplo: el Caribe, donde se busca la exclusividad del lugar), sino que su objetivo es simplemente el de recaudar dinero por parte de la Administración pública y/o de las empresas privadas.

El proceso de privatización del estacionamiento en el dominio público se da principalmente en enclaves turísticos con gran afluencia de visitantes y que se encuentran situados en parajes naturales, con unas características geográficas especiales, donde la disponibilidad de espacio para el aparcamiento de vehículos es reducido. Estos condicionantes favorecen que la Administración

9. <http://ultimahora.es/mallorca/noticias/part-forana/2014/122341/campos-adjudica-orases-covetes-por-periodo-tres-anos-por-000-euros-anuales.html> [consulta: 18 abril 2014].

10. <http://www.diariodemallorca.es/part-forana/2011/05/23/aparcar-coche-controvertidoparking-des-trenc-seguira-costando-ano-6-euros/672157.html> [consulta: 18 abril 2014]. 
pública pueda explotar estas zonas mediante una tasa de estacionamiento, la cual es gestionada o bien directamente por el propio consistorio o mediante el otorgamiento de concesiones a empresas privadas.

En la mayoría de los casos, su implantación se justifica a partir de la necesidad de regular el tráfico en estos espacios, por motivos de seguridad y ambientales. No obstante, la realidad demuestra que los municipios mallorquines han visto en la pseudoprivatización de las zonas públicas el camino para la obtención de nuevos recursos económicos que contribuyan a sustentar las maltrechas arcas municipales, las cuales se han visto afectadas por la actual crisis económica, que ha supuesto una disminución de los ingresos asociados a la actividad constructiva. Por lo tanto, pasada la etapa de bonanza del boom inmobiliario, las administraciones públicas vuelven a centrar nuevamente su mirada hacia el turismo como fuente de recaudación de ingresos que permitan su sustento.

No obstante, a diferencia de otras medidas impulsadas de carácter recaudatorio, este tipo de privatizaciones no solo repercuten sobre los visitantes foráneos de estos espacios de gran interés turístico, sino que también afectan a la población local, quien también se ve obligada a pagar por acceder a estos enclaves de su propia isla y, por tanto, ve limitado su uso y frecuentación en función de su poder adquisitivo. Ello provoca que la mercantilización del espacio público esté provocando un cierto desarraigo de la ciudadanía hacia su propio territorio, a causa de la pérdida de sentido de lo que sería este como símbolo identitario de la población. Así pues, nos encontramos delante de una gran controversia, ya que si, por un lado, estas privatizaciones surgen para lograr nuevos ingresos que permitan sustentar a los servicios públicos, por otro lado, están generando nuevas situaciones de exclusión socioterritorial. En definitiva, estas privatizaciones denotan una escasa voluntad por parte de las instituciones públicas de asumir el rol que tradicionalmente les ha sido asignado por la sociedad: ser responsables del bien común de sus conciudadanos, garantizando una inclusión social y territorial.

\section{Referencias bibliográficas}

Alegre, Joaquín y Pou, Llorenç (2009). Finançament municipal: Els ingresos dels ajuntaments de Mallorca. Consell de Mallorca. Departament de Cooperació Local.

Ardura, Álvaro (2014). «Madrid. Espacio público confiscado: La privatización y resignificación del espacio público en los procesos de transformación material de las plazas del centro de Madrid». En: BonASTra, Quim et al. (eds.). Actas del XIII Coloquio Internacional de Geocrítica: El control del espacio y los espacios de control [en línea]. Barcelona: Universidad de Barcelona. <http://www.ub.edu/geocrit/ coloquio2014/Alvaro\%20Ardura\%20Urquiaga.pdf> [Consulta: 15 mayo 2015].

Arendt, Hannah (2009). La condición humana. Buenos Aires: Paidós.

Astleithner, Florentina y Hamedinger, Alexander (2003). «Urban sustainability as a new form of governance: Obstacle and potentials in the case of Venice». Innovation, 16 (1), 51-73.

Bellet, Carmen (2007). «Los espacios residenciales de tipo privativo y la construcción de la nueva ciudad: Visiones de privatopía». Scripta Nova: Revista Electrónica de Geogra- 
fia y Ciencias Sociales [en línea], XI (245). Barcelona: Universidad de Barcelona, 1 de agosto. <http:/www.ub.es/geocrit/sn/sn-24508.htm> [Consulta: 12 febrero 2014].

Burgos, Silvia Patricia (2011). Uso y apropiación del espacio público en el litoral caribe colombiano: Caso Santa Marta. Bogotá: Instituto de Estudios Caribeños San Andrés Isla, 228. Tesis doctoral dirigida por Francisco Avella.

Carmona, Matthew (2010). «Contemporary Public Space: Critique and Classification. Part One: Critique». Journal of Urban Design, 15 (1), 123-148.

Carmona, Matthew; De Magalhaes, Claudio y Hammond, Leo (2008). Public Space: The Management Dimension. Londres: Routledge.

Cisneros, José (2003). "La privatización del espacio público». Revista Latina de Comunicación Social [en línea], 56. <http://www.ull.es/publicaciones/ latina/20035631cisneros.htm> [Consulta: 15 mayo 2015].

Cruz, Erika et al. (2012). «Las dinámicas de dominación capitalista en el espacio rural: La configuración de paisajes turísticos». Cuadernos de Desarrollo Rural, 9 (69), 151-174.

Diario de Mallorca [en línea]. <http://www.diariodemallorca.es/part-forana/2011/10/09/valldemossa-unico-municipio-necesita-recortes/710173.html> [Consulta: 21 febrero 2014].

Diario de Mallorca [en línea]. <http://www.diariodemallorca.es/part-forana/2011/01/04/informe-municipal-1996-defendio-publico-viales-formentor/633331.html> [Consulta: 21 febrero 2014].

Diario de Mallorca [en línea]. <http://www.diariodemallorca.es/part-forana/2011/05/23/aparcar-coche-controvertido-parking-des-trenc-seguira-costandoano-6-euros/672157.html> [Consulta: 18 abril 2014].

DíAz, Raúl (2013). «Transformación del espacio público desde una lectura de Habermas y nuevas perspectivas críticas desde el espacio cultural latinoamericano». Socioarcis: Revista de la Escuela de Sociología, 3.

Estévez, Brais (2012). "La idea de espacio público en geografía humana: Hacia una conceptualización (crítica) contemporánea». Documents d'Anàlisi Geogràfica, 58 (1), 137-163.

Fainstein, Susan (1994). The city builders: Property, politics, and planning in London and New York. Oxford: Blackwell.

García, Antonio (2004). «Miedo y privatización de los espacios públicos: ¿Hacer o deshacer la ciudad?». VII Coloquio de Geografía Urbana: La Ciudad y el Miedo. Barcelona.

Habermas, Jürgen (1989). The Structural Transformation of the Public Sphere: An Inquiry into a Category of Bourgeois Society. Cambridge: Polity Press.

- (1999). Historia y critica de la opinión pública. México D. F.: Gustavo Gili.

Hiernaux, Daniel y Lindon, Alicia (1996). «El concepto de espacio y el análisis regional». Secuencia, 25, 89-109.

Hughes, George (1999). "Urban revitalization: The use of festive time strategies». Leisure Studies, 18, 119-135.

Jacobs, Jane (1961). The Death and Life of Great American Cities. Nueva York: Random House.

Low, Setha (2005). «Transformaciones del espacio público en la ciudad latinoamericana: Cambios espaciales y prácticas sociales». Bifurcaciones: Revista de Estudios Culturales Urbanos, 5.

McKenzie, Evan (1994). Privatopia: Homeowner Associations and the Raise of Residential Private Government. Yale University Press. 
Mordue, Tom (2007). "Tourism, urban governance and public space». Leisure Studies, 26 (4), 447-462.

Murray, Ivan; Blázquez, Macià; Pons, Antoni (2008). «La explosión turística en las Islas Baleares (1956-2000): Cambios de uso del suelo y metabolismo socioeconómico». En: El paisaje en perspectiva histórica: Formación y transformación del paisaje en el mundo mediterráneo. Zaragoza: Institución Fernando el Católico, 351-375.

Paquot, Thierry (2000). "Villes privées ou privatisées». Urbanisme, 312, 60-62.

Peck, Jamie y Tickell, Adam (2002). «Neoliberalizing space». Antipode, 34 (3), 380-404.

Picornell, Climent (1989). Turisme i territori a les Illes Balears. Universitat de les Illes Balears. Tesis doctoral inédita.

Prada, José (2011). "Privatización del espacio en los nuevos contextos urbanos y socioculturales: El fenómeno de las gated communities». Lurralde: Investigaciones Espaciales, 34, 219-234.

PrÉvôt, Marie-France (2001). «Fragmentación espacial y social: Conceptos y realidades». Perfiles Latinoamericanos, 19.

RaвотNikof, Nora (2005). En busca de un lugar común: El espacio público en la teoría politica contemporánea. México: Instituto de Investigaciones Filosóficas. Universidad Nacional Autónoma de México.

Salvà, Pere (1990). El turisme com a element impulsor del procés d'urbanització a Balears (1960-1989). Palma de Mallorca: Govern Balear. Conselleria de Cultura, Educació i Esports. Institut d'Estudis Baleàrics.

SEnnet, Richard (1994). Carne y piedra: El cuerpo y la ciudad en la cultura occidental. Barcelona: Alianza.

Seguí, Miguel (2006). El turisme a les Illes Balears (1950-2005). Palma de Mallorca: Documenta Balear.

Última Hora [en línea]. <http://ultimahora.es/mallorca/noticias/part-forana/2013/89196/aparcar-lluc-cuesta-ahora-dos-centimos-por-minuto-tiquet-incluye-entrada-museo.html> [Consulta: 21 febrero 2014].

Última Hora [en línea]. <http://ultimahora.es/mallorca/noticias/part-forana/2013/108971/aparcamiento-lluc-cambia-por-tercera-vez-tarifas-para-potenciarllegada-residentes.html> [Consulta: 21 febrero 2014].

Última Hora [en línea]. <http://ultimahora.es/mallorca/noticias/part-forana/2014/122341/campos-adjudica-ora-ses-covetes-por-periodo-tres-anos-por000-euros-anuales.html> [Consulta: 18 abril 2014]. 